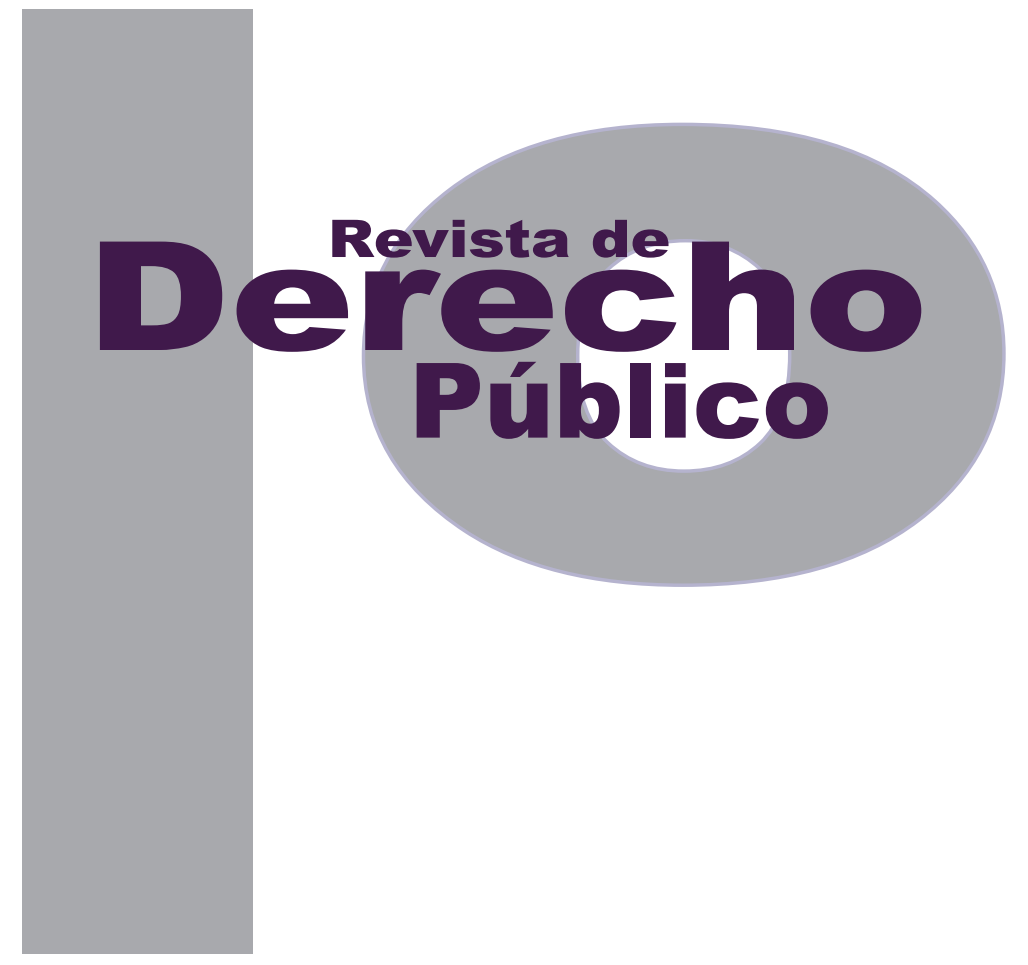

\title{
LA OBJECIÓN DE CONCIENCIA EN COLOMBIA: DE LA AUSENCIA AL RECONOCIMIENTO COMO DERECHO
}

\author{
Cristina Rosero Arteaga \\ ARIADNA TOVAR RAMÍREZ \\ Artículo de investigación científica y tecnológica \\ DOI: http://dx.doi.org/10.15425/redepub.33.2014.16 \\ Universidad de los Andes \\ Facultad de Derecho \\ Revista de Derecho Público N. ${ }^{\circ} 33$ \\ Julio - Diciembre de 2014. ISSN 1909-7778
}




\section{La objeción de conciencia en Colombia: de la ausencia al reconocimiento como derecho}

\section{Resumen}

Este artículo se centra en el análisis de la evolución que ha tenido la figura de la objeción de conciencia en la jurisprudencia de la Corte Constitucional colombiana, en donde ha pasado de recibir poca o ninguna protección constitucional, a un posterior reconocimiento como expresión de las libertades de conciencia y religiosa frente a obligaciones, para finalizar en que actualmente es tratada por la jurisprudencia como un derecho fundamental. Así mismo, se busca evidenciar la existencia de un marco regulatorio general de origen constitucional, aplicable a los distintos ámbitos donde se ejerce la objeción de conciencia, en el que solo se permiten regulaciones específicas y diferenciadas cuando se trata de su ejercicio frente a derechos de terceras personas, y no de su ejercicio frente a obligaciones. Para ello, se expone el resultado del análisis realizado a partir de la revisión jurisprudencial de sentencias de la Corte Constitucional entre los años 1992 y 2013 , en cinco escenarios diferentes.

Palabras clave: libertad de conciencia, libertad de religión, objeción de conciencia, derechos fundamentales.

\section{Conscientious objection in Colombia: The path to recognition as a right}

\section{Abstract}

This paper is focused on the analysis of the evolution of the conscientious objection in the jurisprudence of the Colombian Constitutional Court: at the beginning it has not received constitutional protection or was protected in a restricted manner, then it received recognition as a expression of freedoms of religion and conscience, and nowadays is categorized by the jurisprudence as a fundamental right. Moreover this article intends to illustrate the existence of a constitutional regulatory framework for conscientious objection, design to be applied in the different scenarios where it could be possible to claim it. This framework allows special rules just in the contexts where claiming the right to conscientious objection implies an opposition to other fundamental rights, but not in contexts where is opposed just to obligations. To do this, the article exposes the result of the analysis from the jurisprudential review of decisions of the Constitutional Court from 1992 to 2013 in five different scenarios.

Keywords: freedom of conscience, freedom of religion, conscientious objection, fundamental rights.

\section{A objeção de consciência na Colômbia: da ausência, ao reconhecimento como direito}

\section{Resumo}

Este artigo está centrado na análise da evolução que tem tido a figura da objeção de consciência na jurisprudência da Corte Constitucional colombiana, onde tem passado de receber pouca ou nenhuma proteção constitucional, a um posterior reconhecimento como expressão das liberdades de consciência e religiosa frente a obrigações, para finalizar em que atualmente é tratada pela jurisprudência como um direito fundamental. Assim mesmo, se busca evidenciar a existência de um marco regulatório geral de origem constitucional, aplicável aos distintos âmbitos onde se exerce a objeção de consciência, no que só se permitem regulações específicas e diferenciadas quando se trata de seu exercício frente a direitos de terceiras pessoas, e não de seu exercício frente a obrigações. Para isso, é exposto o resultado da análise realizada a partir da revisão jurisprudencial de sentenças da Corte Constitucional entre os anos 1992 e 2013 em cinco cenários diferentes.

Palavras-chave: liberdade de consciência, liberdade de religião, objeção de consciência, direitos fundamentais. 


\title{
La objeción de conciencia en Colombia: de la ausencia al reconocimiento como derecho*
}

\author{
Cristina Rosero Arteaga** \\ Ariadna Tovar Ramírez ${ }^{* * *}$
}

\begin{abstract}
SUMARIO
Introducción - I. LA NEGACIÓN DE USO DE LA OBJECIÓN DE CONCIENCIA EN LA JURISPRUDENCIA - A. Obligaciones estudiantiles inobjetables - B. El servicio militar obligatorio incluso en contra de la conciencia - II. HACIA UN RECONOCIMIENTO INCIPIENTE - III. EL DERECHO A LA SALUD FRENTE A LA OBJECIÓN DE CONCIENCIA - IV. EL DERECHO A LA OBJECIÓN DE CONCIENCIA - A. El derecho a objetar la prestación del servicio militar - B. El derecho a la objeción de conciencia frente el derecho al aborto legal - V. CONCLUSIONES - Referencias.
\end{abstract}

* Cómo citar este artículo: Rosero Arteaga, C. y Tovar Ramírez, A. (Diciembre, 2014). La objeción de conciencia en Colombia: de la ausencia al reconocimiento como derecho. Revista de Derecho Público, 33. Universidad de los Andes (Colombia).

En el presente artículo se exponen los resultados de investigación del proyecto Estudios de derecho procesal: los principios constitucionales, financiado por el Comité Nacional para el Desarrollo de la Investigación (CONADI), de la Universidad Cooperativa de Colombia - Sede Pasto.

** Abogada de la Universidad de Nariño. Especialista en Instituciones Jurídico Procesales de la Universidad Nacional de Colombia. Candidata a magíster en Derecho Procesal de la Universidad de Medellín. Investigadora del grupo La Minga (categoría B en Colciencias). Se ha desempeñado como directora del Centro de Investigaciones Sociojurídicas de la Universidad Cooperativa de Colombia -Sede Pasto- y decana (E.) de la Facultad de Derecho de la misma universidad. Actualmente es abogada de staff de la organización internacional de derechos humanos Women's Link Worldwide. Correo: cristina4588@gmail.com

*** Abogada y magíster en Derecho de la Universidad de los Andes. Máster I en Derecho Público de la Université des Antilles et de la Guyane (Cayena, Francia) y participante del Diploma de Postítulo "Derechos humanos y mujeres: estrategias jurídicas para la incidencia" de la Universidad de Chile (Santiago de Chile). Entre 2007 y 2009 se desempeñó como abogada en asuntos constitucionales y administrativos en el Consejo de Estado Colombiano y, posteriormente, como abogada litigante en asuntos constitucionales, disciplinarios y administrativos. Actualmente es directora legal y de incidencia, regional Bogotá, de la organización internacional de derechos humanos Women's Link Worldwide. Correo: ariadnatovarramirez@gmail.com 
Introducción

El reconocimiento y ejercicio de la objeción de conciencia en el marco constitucional colombiano ha tenido diferentes etapas, así como avances paralelos y otras veces divergentes, en distintos escenarios. Del análisis de la jurisprudencia se puede determinar que ha habido un cambio de postura de la Corte Constitucional, a través de los años, frente a la ausencia de reconocimiento de la objeción de conciencia como una expresión de las libertades de conciencia y de religión, una segunda etapa en que efectivamente se empezó a reconocer como parte de estas libertades, para llegar, actualmente, a su reconocimiento como derecho. El ejercicio de este derecho tiene límites, requisitos y procedimientos que aunque toman formas distintas dependiendo del escenario, pueden agruparse bajo un mismo marco regulatorio. Así mismo, en aplicación de este marco, el ejercicio de este derecho tendrá unas limitaciones mayores cuando se confronta con los derechos de terceros, que cuando se trata de su ejercicio frente a obligaciones de tipo legal o contractual.

Este artículo presenta resultados de una investigación jurídica, con metodología cualitativa de tipo descriptivo, cuya técnica fue la revisión jurisprudencial. Se usaron fichas jurisprudenciales como instrumento para la recolección de la información, y el análisis de esta se dirigió a identificar la evolución de la figura de la objeción de conciencia en la jurisprudencia constitucional colombiana y su grado de reconocimiento o protección en cinco escenarios: (i) frente a obligaciones de raigambre académica y laboral, (ii) frente a la obligación de prestar juramento en los servicios médicos y por los profesionales de la salud, (iii) en el servicio militar obligatorio, y (iv) frente a la interrupción voluntaria del embarazo (IVE). Para tal fin se seleccionaron un total de 36 sentencias y 9 salvamentos de voto, proferidos entre los años 1992 y 2013.

A partir de un análisis transversal, se integraron los diferentes escenarios frente a la evolución de la figura de la objeción de conciencia a través del tiempo. Así, el escrito se divide en cuatro partes: i) la ausencia del reconocimiento de la objeción de conciencia como expresión de las libertades de conciencia, religión o pensamiento, y como derecho; ii) el uso de la objeción como resultado de las libertades señaladas; iii) el derecho a la salud y la objeción de conciencia; y iv) el reconocimiento de la objeción de conciencia como un derecho. Es necesario resaltar que estas etapas no coinciden con un relato cronológico exacto, pues, en ocasiones, algunos de los escenarios estudiados inician en un estadio más avanzado que en otros, como es el caso de la objeción de conciencia en servicios de salud, o dan un salto entre la negativa a proteger la figura y su reconocimiento como derecho, de lo cual es ejemplo el servicio militar obligatorio.

\section{LA NEGACIÓN DE USO DE LA OBJECIÓN DE CONCIENCIA EN LA JURISPRUDENCIA}

En términos de períodos de tiempo y de escenarios, la etapa de negación del ejercicio de la libertad de conciencia para objetar el cumpli- 
miento de obligaciones va desde el inicio de la jurisprudencia de la Corte Constitucional hasta aproximadamente 2001, y abarca los escenarios de objeción frente a obligaciones académicas y frente a la obligación de prestar el servicio militar.

\section{A. Obligaciones estudiantiles inobjetables}

Los primeros intentos de ejercicio de la objeción de conciencia en el ámbito educativo se presentaron con estudiantes que objetaron el horario académico, es decir, una obligación contractual derivada de su matrícula, con base en sus convicciones religiosas.

Los casos analizados se refieren a estudiantes pertenecientes a la Iglesia Adventista del Séptimo Día que se niegan a realizar actividades académicas o laborales desde las 6:00 p. m. de cada viernes hasta las 6:00 p. m. del sábado, debido a que tal obligación va en contra del mandato religioso que les exige dedicar ese período de tiempo únicamente para las ceremonias religiosas. De otra parte, la jurisprudencia también ha analizado casos de estudiantes Testigos de Jehová que objetan la participación en actividades cívicas, porque entran en la categoría de adoración de símbolos, prohibida por su culto.

En el caso de estudiantes de la Iglesia Adventista del Séptimo Día que objetaban el horario que coincidía con sus obligaciones religiosas, inicialmente la Corte consideró que la negativa de instituciones educativas a excusar a sus es- tudiantes durante estos horarios no les vulneraba el derecho a la libertad religiosa.

Así, en el caso de una estudiante que pidió protección ante la negativa de la universidad en que estudiaba de permitirle no acudir a las actividades académicas del sábado, bajo el compromiso de presentar trabajos o realizar actividades que compensaran su ausencia, la Corte Constitucional determinó que no había violación de sus derechos debido a que en virtud de la autonomía universitaria, el establecimiento tenía el derecho de fijar los horarios de clase de forma general. En consecuencia, correspondía a la estudiante elegir entre cumplir con su deber religioso o con su deber académico (Corte Constitucional, 1993c).

El magistrado Cifuentes Muñoz (1993) salvó el voto argumentando que la libertad de cultos es de aplicación inmediata, mientras que la autonomía universitaria no lo es, por lo que la primera tiene mayor fuerza normativa. Por tanto, afirmó que era necesario buscar una solución que tuviera en cuenta ambos intereses, sin que fuera posible imponer a la estudiante la obligación de escoger entre renunciar a su culto o a su educación. Así, ante la existencia de otras actividades académicas que podrían reemplazar las ausencias de los sábados, y por tratarse de una petición muy seria de la estudiante de protección a sus derechos fundamentales, el no plantear alternativas académicas constituiría discriminación.

En sentido similar, la Corte ha sido uniforme en que no hay violación de la libertad religiosa de 
los estudiantes Testigos de Jehová cuando no se les excusa de la participación en actos de conmemoración patriótica. La conclusión a la que Ilega la Corte es que los símbolos patrios representan la pertenencia a un país y, como no son un objeto divino, no pueden asimilarse los actos de honra a estos con la adoración religiosa.

En un primer caso llevado ante la Corte, una estudiante menor de edad solicitó al colegio en que estaba inscrita que se le excusara de los actos preparatorios y de la participación en el desfile del 20 de julio, porque de acuerdo con su religión no podía adorar símbolos. Luego de su inasistencia al desfile, se le informó que le había sido negada la petición y recibió la calificación de 1.0 en la asignatura de educación física. La Corte determinó que no hubo violación a la libertad de conciencia ni de cultos porque participar en un acto patriótico no es sinónimo de adoración, en cuanto la patria no es algo divino, sino demuestra un sentimiento de pertenencia a la Nación (Corte Constitucional, 1995a). Por el contrario, la Corte encontró una violación al debido proceso en cuanto la actividad fue incluida como parte del programa académico con posteridad a la matrícula y se le aplicó a la estudiante una sanción para un comportamiento no previsto como falta disciplinaria.

Posteriormente, la Corte analizó la tutela interpuesta por unos estudiantes Testigos de Jehová a quienes se les había cancelado su cupo para el siguiente año escolar, a pesar de que tenían un excelente récord académico y disciplinario, en razón de que no izaban bandera, no participaban en desfiles cívicos ni en homenajes a símbolos patrios. La Corte consideró que aunque la Constitución le da un lugar especial a la libertad de cultos, esta no es absoluta, y en el caso concreto no se desconocía porque el deber cívico de izar la bandera fue aceptado por los estudiantes al firmar la matrícula y porque la exaltación de los símbolos patrios no podía considerarse violatoria de estos derechos fundamentales por tratarse de una forma de expresar pertenencia nacional (Corte Constitucional, 1999).

El magistrado Cifuentes Muñoz (1999) salvó el voto en esta decisión, al estimar que el análisis de la violación del derecho a la libertad religiosa no puede partir de la asunción del concepto de adoración derivado de su definición en el diccionario, sino teniendo en cuenta lo que implicaba para los demandantes. Considerar que los símbolos patrios no son divinos y, por tanto, no pueden ser objeto de adoración, según el magistrado desconoció la libertad de cultos porque se impone una compresión de la manifestación religiosa ajena al discurso de la comunidad y va en contra de la coherencia entre manifestaciones internas y externas. Además, no asistir a los actos cívicos no afecta ni los derechos de terceros ni la salud, seguridad o moralidad públicas. Agregó que los contenidos de los proyectos educativos deben ser neutrales, característica que resulta afectada cuando se desestiman razones personales, de conciencia o religiosas que llevan a rechazar lo que representan los símbolos, y cuando se imponen sanciones por este rechazo. 


\section{B. El servicio militar obligatorio incluso en contra de la conciencia}

En relación con la prestación del servicio militar obligatorio, en un inicio se negó por completo la posibilidad de objetarlo principalmente con base en argumentos relativos a i) la obligatoriedad constitucional del servicio y la existencia de exenciones taxativas de carácter legal, ii) la falta de positivización de la objeción de conciencia en el ordenamiento colombiano y iii) en el argumento histórico del presunto rechazo de su inclusión en el texto constitucional por parte de la Asamblea Nacional Constituyente.

Así, es relevante referirse al primer caso de la línea jurisprudencial sobre el tema, en el que los accionantes se oponían a la prestación del servicio militar para el que habían sido seleccionados, con fundamento en su pertenencia a la iglesia menonita "Dios es amor", que rechaza participar en organismos creados para imponer o monopolizar la fuerza (Corte Constitucional, 1992).

La Corte denegó la protección solicitada, con base en el principio de igualdad porque consideró que el servicio militar es una obligación para todos los hombres en Colombia. Así mismo, estableció que la libertad de conciencia no necesariamente protegía la objeción de conciencia y que el servicio militar en sí mismo no afectaba la conciencia individual porque podía cumplirse con funciones diferentes a tomar las armas, aunque esta modalidad no se encontraba establecida en el ordenamiento, pues fue rechazada por la Asamblea Constituyente. Agregó el Tribu- nal, que las condiciones para poder eximirse del servicio se encontraban delimitadas en el artículo 21 de la Ley $1^{\text {a }}$ de 1945, sin que se incluyera la libertad de conciencia entre ellas (Corte Constitucional, 1992).

La posición de la Corte en este primer pronunciamiento se repite en las siguientes decisiones al respecto, que en principio, siguen la misma línea argumentativa, ${ }^{1}$ y es retomada, incluso, en casos en que la objeción de conciencia al servicio militar no era el problema jurídico central.

La Corte reforzó su postura al resolver el caso de un joven que fue reclutado por las Fuerzas Armadas colombianas a pesar de ser clérigo del credo de los Testigos de Jehová, que prohíbe realizar acciones como elevar juramentos a la bandera o el entrenamiento para el combate (Corte Constitucional, 1995b). La Corte reiteró que las causales de exoneración del servicio militar obligatorio son taxativas, que la objeción de conciencia no estaba contemplada en la normatividad y que el derecho a la libertad de conciencia no es absoluto, pues halla límites en el interés general. Finalmente, frente al punto de ostentar la calidad de clérigo como causal de exención del servicio militar obligatorio, la Corte afirmó que la formación de los ministros de esta iglesia debía ser equiparable a la de los centros de educación superior aprobados por el Ministerio de Educación Nacional (Corte Constitucional, 1995b).

Por otra parte, en sentencia C-740 de 2001, al examinar varias normas del Código Penal Mili-

1 Ver sentencias T-244 de 199, C-511 de 1994 y C-561 de 1995. 
tar, la Corte hizo énfasis en la obligatoriedad del servicio militar y en que esta no podía resultar afectada por la objeción de conciencia, aunque no se pronunció de fondo sobre el tema, pues afirmó que solo podría hacerlo si se hubiera incluido en los cargos específicos de la demanda (Corte Constitucional, 2001a).

Respecto a la posición predominante de la Corte que desconocía la posibilidad de hacer uso de la objeción de conciencia frente al servicio militar, algunos magistrados expresaron en sus salvamentos de voto posturas que afirmaban la existencia de la objeción de conciencia dentro del derecho a la libertad de conciencia.

Así, en el salvamento de voto a la sentencia C-511 de 1994, los entonces magistrados Cifuentes, Gaviria y Martínez (1994) manifestaron que debía garantizarse el ejercicio de la objeción de conciencia, pues esta se desprende de forma directa de la Constitución. Frente al argumento de tipo histórico, según el cual no tenía cabida su aplicación debido al rechazo de la Asamblea Nacional Constituyente, concluyeron que la intención de esta no fue su exclusión total del ordenamiento, y adujeron que por encima de los argumentos históricos debían primar las interpretaciones sistemática y finalista. Así, ante la evidente colisión de dos normas constitucionales (arts. 18 y 216) y en virtud de la aplicación del derecho internacional, debería reconocerse la objeción de conciencia al servicio militar obligatorio.

Varios años después, el magistrado Cepeda Espinosa (2001) en salvamento de voto a la sen- tencia C-740 de 2001 expresó que la Corte debió abordar en extenso el tema de armonización entre el deber de tomar las armas y la libertad de conciencia, debido a que con independencia de los cargos formulados, las normas demandadas debían juzgarse frente a toda la Constitución. Afirmó que la libertad de conciencia comprende la definición básica acerca de quién se es, y aclaró que si bien la proposición de una inclusión amplia de la objeción de conciencia fue rechazada en la Asamblea Nacional Constituyente, hubo otra y específica al porte de armas, que fue aprobada en plenaria en primera vuelta y que finalmente no se incluyó porque se dedujo que la redacción de la libertad de conciencia era lo suficientemente amplia. Adicionó que la misma Constitución establece que la no enunciación de un derecho no puede interpretarse como negación de otros inherentes a la persona humana.

El magistrado Araújo Rentería (2001) también se pronunció frente a la sentencia C-740 de 2001. En su concepto no podría cambiarse el estatus jurídico de una persona, de civil a militar, mediante un acto administrativo, y tampoco podría afirmarse la inexistencia de la objeción de conciencia ante la ausencia de su consagración expresa, porque los géneros como la libertad de conciencia siempre incluyen a las especies, como la objeción.

También el entonces magistrado Montealegre Lynnet (2001) se pronunció en el caso en mención, señalando que la postura expresada en la sentencia según la cual el deber de tomar las armas sería un deber absoluto, no es defendi- 
ble en un Estado social de derecho en que se impone el máximo respeto por la autonomía personal.

\section{HACIA UN RECONOCIMIENTO INCIPIENTE}

Varios años después de expedidas las decisiones de la Corte en que negó la protección de las libertades de conciencia y religiosa ante la imposibilidad de excusarse de obligaciones académicas cuando estas se daban en el mismo horario del Sabath, el alto Tribunal modificó su posición. A partir de ese momento para la Corte la libertad religiosa protege las manifestaciones internas y externas de pertenencia a una religión o credo, y cuando estas entran en conflicto con obligaciones de tipo académico o laboral, es decir, con obligaciones contractuales, es posible objetar al deber con base en las convicciones religiosas.

El cambio en la postura de la Corte frente al tema es notable en el caso de una estudiante del Servicio Nacional de Aprendizaje (SENA), que pertenecía a la Iglesia Adventista del Séptimo Día y solicitó al profesor de un módulo dictado el sábado que le asignara otras actividades en reemplazo de su asistencia a clase ese día. Ante la falta de acuerdo con el docente se dirigió al director del centro de servicios y a pesar de que ella informó de su situación, le fue cancelada la matrícula.

La Corte expresó que la libertad religiosa protege no solo las manifestaciones internas, sino también las externas como la guarda del sábado para las ceremonias religiosas por parte de los fieles de la Iglesia Adventista del Séptimo Día, por lo que su protección constitucional implica que en centros educativos y laborales se busquen actividades alternativas para reemplazar las previstas para el sábado. En criterio de la Corte, esta manifestación religiosa no puede ser objeto de transacción por ser parte del núcleo esencial de la libertad religiosa. La condición para invocar esta protección es, de acuerdo con la Corte, informar antes de iniciar las clases o en un tiempo razonable posterior al inicio de estas (Corte Constitucional, 2005a).

Así mismo, en esta nueva etapa se protegió la libertad religiosa en el ámbito laboral, como lo demuestra el caso de una trabajadora de un supermercado cuya jornada laboral fue incrementada en tres horas que debía cumplir durante el día sábado, y a la que la empresa le negó la solicitud de compensar las horas en un día distinto. La Corte manifestó que las libertades religiosa y de conciencia contemplan el realizar ciertos actos, así como la negativa a realizar otros. Para el caso de la Iglesia Adventista, la Corte resaltó que la jurisprudencia ya había reconocido el derecho a guardar el Sabath y consideró que no era posible desconocer el derecho a la libertad religiosa con base en la facultad legal del empleador para fijar horarios (Corte Constitucional, 2001c).

Otra de las sentencias se presentó a raíz del caso de un trabajador de una clínica, también miembro de la Iglesia Adventista, que pactó su jornada laboral fuera del Sabath, y al que luego 
el empleador le cambió el horario y le negó sus solicitudes de compensación del horario entre semana, lo que causó que fuera despedido. Para resolver el caso, la Corte citó diversas sentencias sobre el tema ${ }^{2}$ y concluyó que debido a que el actor había notificado su orientación religiosa numerosas veces, se desconocieron sus derechos al adoptar medidas desproporcionadas como el despido. La Corte reiteró que para los miembros de la Iglesia Adventista, el derecho a la libertad religiosa contempla la protección del Sabath (Corte Constitucional, 2009a).

En la sentencia T-839 de 2009, una de las más destacadas sobre el tema, el accionante presentó la acción debido a que siendo parte de la Iglesia Adventista no pudo participar en el IV Concurso de Formación Judicial para proveer cargos de jueces y magistrados, porque este se programó durante el Sabath. La Sala Administrativa del Consejo Superior de la Judicatura negó las excusas por su inasistencia, a pesar de que él notificó de su imposibilidad de asistir. La Corte recordó que el derecho a guardar el Sabath hace parte del derecho a la libertad religiosa, ${ }^{3}$ y manifestó que ante una creencia seria del actor se violó su libertad de religión por obligarle a realizar actividades que iban en contra de tal creencia, como el requisito de participar en el concurso para acceder a cargos públicos. La exclusión no proporcionada ni razonable de los adventistas de este tipo de concursos im-

2 Las sentencias T-593A de 1993, T-588 de 1998, T-877 de 1999, T-982 de 2001, T-026 de 2005, T-448 de 2007 y T-044 de 2008.

3 La Corte cita las sentencias T-593A de 1993, T-588 de 1998, T-982 de 2001, T-026 de 2005, T-044 de 2008, T-448 de 2007 y T-329 de 2009. plicaba una discriminación a las personas que pertenecen a esta religión (Corte Constitucional, 2009d).

En una sentencia con ponencia del magistrado Cifuentes Muñoz, quien había salvado su voto en dos sentencias de la primera etapa de la Corte en que se negó la protección de la libertad de conciencia, ${ }^{4}$ se abordó el estudio de una tutela interpuesta por los padres en representación de sus hijos, porque en la institución educativa en que estaban inscritos se les exigía aprobar el logro “ejecución de ritmos”, prohibido por el credo de la Iglesia Pentecostal Unida de Colombia.

La Corte expresó que para que haya una objeción legítima y protegida debe constatarse únicamente que esta sea sincera y genuina, y no un pretexto para obviar la obligación. Además, es necesario tener en cuenta si los objetivos educativos pueden obtenerse a través de otros medios que permitan la eliminación de los fundamentos de la objeción. En criterio de la Corte, las condiciones descritas no fueron cumplidas por el plantel educativo ni por el profesor, al insistir en la ejecución de las danzas pero con ritmos de la religión a la que pertenecen los demandantes. En consecuencia, ordenó que para aprobar el logro se estableciera otra prueba que no lesionara la libertad religiosa y de conciencia de los demandantes (Corte Constitucional, 1998).

No obstante, no en todos los casos de esta época los integrantes de la Iglesia Adventista pudie- 
ron objetar obligaciones legales o contractuales con base en sus convicciones. En un pronunciamiento previo al anteriormente referenciado, se estudió el caso de dos personas pertenecientes a dicha iglesia, a quienes la Registraduría Nacional del Estado Civil citó como jurados de votación durante el Sabath, y que podían ser sancionadas porque no asistieron. Aunque la acción fue negada porque se constató que la Registraduría no iba a imponer sanción alguna, la Corte sostuvo que era en extremo difícil conocer la fe que profesan todos los ciudadanos asignables como jurados de votación. Además, citar a jurados pertenecientes a la Iglesia Adventista no afecta en extremo el derecho a la libertad religiosa, pues si bien el respeto del Sabath es fundamental en su sistema de creencias, la realización de elecciones no demanda su participación todos los sábados (Corte Constitucional, 2004b).

La negativa de proteger la libertad religiosa en este caso provino de que no había una vulneración derivada del ejercicio de la objeción, es decir, no se iba a imponer la sanción correspondiente por la ausencia de los jurados. Ahora bien, la Corte al efectuar la valoración de si convocar a jurados el sábado iba en contra de la libertad religiosa de los adventistas, concluyó que no se veía afectada dicha libertad, porque la obligación no era permanente, es decir, podría considerarse proporcional, en tanto la obligación era temporal. Situación distinta a la del caso del creyente adventista que no pudo participar en el concurso para proveer cargos públicos, porque ello implicaba su asistencia durante varios sábados.
En este punto es importante anotar que en el caso de la obligación de prestar juramento, la jurisprudencia lo ha tratado, en una ocasión como un formalismo que puede ser objetado y reemplazado por otra expresión, y en otra como una práctica que buscaba garantizar la buena fe y el apego a la verdad de las personas, por lo que no vulneraba las libertades de conciencia y religiosa. ${ }^{5}$

\section{EL DERECHO A LA SALUD FRENTE A LA OBJECIÓN DE CONCIENCIA}

En el campo de la prestación de servicios de saIud las libertades de conciencia y de religión se

5 En un primer pronunciamiento, en sentencia T-547 de 1993, la Corte estudió el caso de un ciudadano que acudió a la Policía Judicial para interponer una denuncia por la desaparición de su hija, y se le requirió prestar juramento para poder presentarla, aspecto para el que estaba impedido por su orientación religiosa (Corte Constitucional, 1993b). La Corte determinó que la Ley $1^{\circ}$ de 1993 permite reemplazar la palabra juramento en casos de extranjeros, por un protesto, si su religión no les permite jurar. Bajo ese entendido, concluyó que si para los extranjeros existe la posibilidad de utilizar una palabra diferente al juramento cuando se trate de impedimentos relativos a su conciencia, no existe razón alguna para que a los nacionales colombianos no se les permita ejercer el derecho a la libertad de conciencia. Por lo anterior dispuso que en los casos en que la persona no pudiera jurar por razones de conciencia, era posible usar otra palabra, entendiendo que por el principio de buena fe se compromete a decir la verdad (Corte Constitucional, 1993b).

En la segunda sentencia, la C-616 de 1997, no obstante, la Corte estudió la constitucionalidad de las expresiones "bajo juramento", "bajo la gravedad del juramento" o "jurada", contenidas en diversos apartes del Código de Procedimiento Civil. La Corte repasó las subreglas hasta entonces establecidas frente a la libertad de conciencia y religiosa, así como la historia del juramento en el ordenamiento legal. Al efecto, determinó que el juramento es un simple rito o solemnidad procesal, un mero formalismo ajeno a todo contenido religioso, que es empleado para poner de presente la obligación de observar buena fe en la manifestación de la verdad, y para derivar una responsabilidad penal. Por lo anterior, estableció que la obligación de jurar impuesta o regulada por las normas bajo estudio no violentaba las libertades de conciencia y religiosa. La posibilidad de introducir excepciones a la obligación de prestar juramento, permitiendo al respecto la objeción de conciencia, llevaría a vulnerar el principio de igualdad, pues quienes la propusieran quedarían desvinculados de la responsabilidad penal que se derivaría del hecho de faltar a la verdad (Corte Constitucional, 1997). 
han ejercido principalmente por pacientes que con base en sus creencias, se niegan a recibir transfusiones como parte del tratamiento de una enfermedad o como parte de las actividades necesarias para realizar un procedimiento.

En este ámbito nos encontramos en el ejercicio de la libertad religiosa de usuarios y usuarias del sistema de salud, en el componente de esta libertad que les permite actuar de forma externa de acuerdo con sus convicciones internas, y no en el ejercicio del derecho a la objeción de conciencia, porque en los casos analizados quienes hacen uso de su libertad religiosa para oponerse a la realización de transfusiones en su tratamiento no se oponen a una obligación legal, sino que escogen entre tratamientos posibles aquel que no va en contra de sus convicciones, o se niegan a recibir la transfusión, incluso cuando es la única posibilidad de curación o tratamiento.

Aun cuando no se trata en estricto del ejercicio de la objeción de conciencia, se resalta que las decisiones de la Corte Constitucional al resolver estos casos sí arrojan reglas muy importantes acerca del marco del ejercicio de la libertad religiosa y sus límites. En primer lugar, la Corte indica que aunque la libertad religiosa es de suma importancia para una Constitución que, como la de 1991, aboga por este derecho (Corte Constitucional, 2005b y 2010b), no es absoluta y tiene límites que se encuentran de manera genérica en los derechos fundamentales de otras personas y en la moralidad, la seguridad, la salud y el bien públicos (Corte Constitucional, 1994a, 2002b y 2010b).
En segundo lugar, como una aplicación precisa a la resolución de los casos, la Corte Constitucional ha indicado que el ejercicio de las creencias religiosas no puede llevar a poner en riesgo o disponer de la vida e integridad propia, ni mucho menos la de terceros (Corte Constitucional, 1994a, 1996, 2002a y 2002b). Así mismo, tampoco puede usarse para atentar contra la dignidad humana (Corte Constitucional, 2002b y 2010b).

Es relevante señalar que estas reglas han estado presentes en la jurisprudencia de salud desde el período en que se negaba la protección al ejercicio de la objeción de conciencia en ámbitos como el de las obligaciones estudiantiles o la prestación del servicio militar obligatorio, y continuó durante el período en que en estos mismos ámbitos y el laboral fue reconocida como expresión de las libertades de conciencia y religiosa.

En el caso de niños, niñas o adolescentes que se niegan a que se les realicen transfusiones, o cuyos padres se niegan a autorizarlas, ${ }^{6}$ la Corte ha sido enfática en que sus derechos a la vida y a la integridad prevalecen sobre el ejercicio de la libertad religiosa de sus padres y la propia. Esta regla constitucional encuentra coherencia en el Código de la Infancia y la Adolescencia que

6 En la sentencia T-411 de 1994, con ponencia del magistrado Vladimiro Naranjo Mesa, se analizó el caso en que los padres de un bebé de diez meses que sufría de bronconeumonía, desnutrición y deshidratación, se negaban a permitir su hospitalización con base en sus convicciones religiosas. En la sentencia T-474 de 1996, M. P. Fabio Morón Díaz, la Corte analizó el caso de un adolescente de 16 años que se negaba a recibir transfusiones, con base en sus convicciones religiosas, a pesar de que era previsible que fueran necesarias para el tratamiento del cáncer que tenía en una de sus rodillas. 
autoriza al personal médico a actuar de manera inmediata en casos de peligro inminente para la vida e integridad personal de dicha población, disposición respaldada por la Corte Constitucional (2011c).

En el caso de personas adultas que se han negado a recibir transfusiones, en las decisiones judiciales se determinó que se respeta el ejercicio de la libertad religiosa, previo consentimiento informado sobre el tratamiento y las consecuencias de la negativa a realizar determinado procedimiento (Corte Constitucional, 2002a y 2005b), siempre y cuando este ejercicio no ponga en riesgo la vida e integridad propias. Sin embargo, en un caso de 2010 donde el tratamiento rehusado era el que de acuerdo con los profesionales de la salud podría curar al paciente, la Corte permitió el ejercicio de la libertad religiosa por parte de este último, incluso bajo el entendido de que podía haber un riesgo para su salud (Corte Constitucional, 2010b).

En efecto, la Corte estudió el caso de una persona enferma que requería un trasplante de médula como tratamiento curativo, y que ante la negativa a realizarse transfusiones por motivos religiosos había sido tratada con esteroides. El paciente solicitaba la realización de un tratamiento del que le había hablado su médico tratante, sin embargo, la empresa promotora de salud (EPS) señaló que dicho tratamiento no era curativo y no existía en Colombia porque no contaba con el registro sanitario del Instituto Nacional de Vigilancia de Medicamentos y Alimentos (Invima). La Corte partió de la base de que la persona tenía derecho a elegir el tratamiento que se ajustaba a sus convicciones, previo consentimiento informado, aunque según criterio médico no fuera el más idóneo o el curativo. Agregó que una persona se puede rehusar a recibir un tratamiento específico, siempre que no ponga en riesgo su vida, su integridad personal o su salud.

Ahora bien, dado que en este caso el trasplante al que se rehusaba el paciente era el tratamiento curativo, la Corte determinó que existía una obligación de tratamiento alternativo que conciliara el derecho a la salud con la libertad de conciencia del paciente. Por lo tanto, ordenó a la EPS encontrar un tratamiento avalado por el Invima, y en caso de no existir dicho tratamiento alternativo, respetar la decisión del paciente sobre realizarse o no el trasplante (Corte Constitucional, 2010b).

Para este caso, es importante referirse al salvamento de voto del entonces magistrado Henao Pérez (2010), quien disintió de la decisión tomada en el caso, por considerar que no había violación de la libertad religiosa del paciente, pues en ningún momento fue obligado a recibir el trasplante. Para el magistrado esta controversia se refería al derecho a la salud que tampoco había sido violado, porque el tratamiento alternativo al solicitado, es decir, la provisión de esteroides, ya había sido dado por la EPS.

En el ámbito de la salud, un caso que aborda el ejercicio de la objeción de conciencia es el de los miembros de un equipo de profesionales de la salud que se negaron a realizar una cirugía a una mujer, ante la reticencia de esta a recibir 
transfusiones sanguíneas, pues era peligroso practicar la intervención quirúrgica sin tener la posibilidad de hacer trasfusiones en caso de requerirse. La mujer que solicitó la operación interpuso la acción de tutela para ser intervenida. La entidad demandada respondió que la accionante podía acudir a otra entidad, y que la intervención no era urgente porque no estaba hospitalizada ni en riesgo de muerte por la ausencia de la cirugía.

En este caso la Corte señaló que la libertad religiosa no podía dañar o amenazar la vida, la integridad o la dignidad humana, y que en una situación en que se enfrentase la libertad religiosa con el derecho a la vida de una persona, siempre debería prevalecer este último derecho. Agregó la Corte que las normas de ética médica facultan a los profesionales de la salud a rehusarse a brindar un tratamiento cuando no se dan las condiciones para un libre y correcto ejercicio de la profesión, y por esta ausencia de condiciones pueda resultar afectada la salud del o de la paciente. La Corte consideró que esta situación se enmarcaba en la figura de objeción médica o sanitaria, que pueden ejercen los profesionales de la salud para evitar el cumplimiento de una obligación, en este caso una de tipo contractual para la prestación del servicio de salud, ante la falta de las condiciones necesarias para ejercer su actividad profesional de acuerdo con las reglas de la Lex Artis.

Con base en los anteriores argumentos, el alto Tribunal concluyó que la demandante podía buscar otro proveedor que estuviera dispuesto a realizarle la cirugía sin recurrir a trasfusiones sanguíneas, salvo que la omisión de realizar la cirugía conllevara un riesgo para su vida o se requiriera como parte de la atención clínica inmediata (Corte Constitucional, 2002b).

En este caso, que corresponde a una época en que recientemente se habían abordado los casos de objeción a obligaciones laborales como protegibles bajo la libertad de conciencia, y en que aún no se reconocía la posibilidad de objetar conciencia al servicio militar obligatorio, posiblemente la resolución a favor de la protección de la objeción de conciencia resultó facilitada porque la Ley 23 de 1981 sobre Ética Médica, ${ }^{7}$ ya consagraba expresamente la posibilidad de objetar conciencia, salvo en casos de urgencia o donde peligre la vida del paciente.

\section{EL DERECHO A LA OBJECIÓN DE CONCIENCIA}

La Corte Constitucional empezó a usar el término derecho a la objeción de conciencia por primera vez en 2009, en dos ámbitos distintos. Por una parte, frente a la obligación del servicio militar, y por otra, frente a la interrupción voluntaria del embarazo, como se mostrará a continuación.

Ley 23 de 1981. "Artículo 6º. El médico rehusará la prestación de sus servicios para actos que sean contrarios a la moral, y cuando existan condiciones que interfieran el libre y correcto ejercicio de la profesión".

Artículo 7o. Cuando no se trate de casos de urgencia, el médico podrá excusarse de asistir a un enfermo o interrumpir la prestación de sus servicios, en razón de los siguientes motivos:
a) Que el caso no corresponda a su especialidad;
b) Que el paciente reciba la atención de otro profesional que excluya la suya;
c) Que el enfermo rehúse cumplir las indicaciones prescritas." 


\section{A. El derecho a objetar la prestación del servicio militar}

En 2009, en la sentencia hito C-728, la Corte reconoció la existencia de la objeción de conciencia frente al servicio militar al estudiar una acción de inconstitucionalidad interpuesta en contra del artículo 27 de la Ley 48 de 1993, ${ }^{8}$ por la violación de los derechos a la igualdad, a la libertad de conciencia y de cultos, derivada de la omisión legislativa consistente en no incluir la objeción de conciencia en las exenciones al servicio militar obligatorio. La Corte se pronunció de fondo, una vez superada la cuestión de la inexistencia de cosa juzgada, y concluyó que no podía proyectarse la omisión legislativa sobre la norma demandada porque existían diferentes alternativas constitucionalmente admisibles. En consecuencia, concluyó que procedía una declaratoria de inexequibilidad diferida para que el Congreso tuviera tiempo de escoger entre las alternativas.

En cuanto a la objeción de conciencia, la Corte hizo una revisión de su jurisprudencia y afirmó que tenía razones para apartarse de sus propias decisiones. Con base en la lectura armónica de los artículos 18 y 19 de la Constitución, junto con las normas demandadas, el alto Tribunal determinó que sí podía ejercerse la objeción de conciencia frente al servicio militar obligatorio,

8 ARTÍCULO 27. EXENCIONES EN TODO TIEMPO: Están exentos de prestar el servicio militar en todo tiempo y no pagan cuota de compensación militar:

a. Los limitados físicos y sensoriales permanentes.

b. Los indígenas que residan en su territorio y conserven su integridad cultural, social y económica. (Congreso de la República de Colombia, 1993). porque no era razonable obligar a personas a cumplirlo cuando los fines de aportar a la Nación y a la cohesión social se podían conseguir por otros medios. De esa forma, se podía armonizar la jurisprudencia constitucional con los referentes del bloque de constitucionalidad. ${ }^{9}$

La Corte consideró que el objetor tenía la obligación de probar las manifestaciones externas de sus convicciones que pueden ser de carácter religioso, ético, moral o filosófico (Corte Constitucional, 2009c). Y sobre las características de las convicciones, señaló:

Que sean profundas implica que no son una convicción o una creencia personal superficial, sino que afecta de manera integral su vida y su forma de ser, así como la totalidad de sus decisiones y apreciaciones.

Que sean fijas, implica que no son móviles, que no se trata de convicciones o creencias que pueden ser modificadas fácil o rápidamente. Creencias o convicciones que tan sólo hace poco tiempo se alega tener.

Finalmente, que sean sinceras implica que son honestas, que no son falsas, acomodaticias o estratégicas (Corte Constitucional, 2009d).

Aclaró la Corte que mientras no fuera regulado el ejercicio de la objeción de conciencia por el legislador, esta debería tramitarse "de forma imparcial y neutral, de acuerdo con las reglas

9

Resolución 1989/59 de la Comisión de Derechos Humanos de las Naciones Unidas, en la que se recomienda adoptar la objeción de conciencia y establecer servicios alternativos para objetores; Observación General n. ${ }^{\circ} 22$ de 1993 del Comité de Derechos Humanos de Naciones Unidas y Observaciones finales del Comité de Derechos Humanos de Naciones Unidas: Colombia. 
del debido proceso" y que podía usarse la tutela para proteger este derecho fundamental (Corte Constitucional, 2009c).

La sentencia tuvo salvamentos de voto de los magistrados Calle, Henao, Palacio y Vargas, quienes manifestaron que sí existió una omisión legislativa relativa en el artículo 27 de la Ley 48 de 1993. Para ellos, la distinción entre personas eximidas en todo tiempo por características objetivas y por razones subjetivas no es teóricamente sólida, ni está incluida en la ley, y por el contrario, oscurece y minimiza la distinción que sí contempla la Constitución. En su concepto, los argumentos expuestos en la sentencia no justificaban el trato discriminatorio que debió ser corregido por la Sala Plena.

En casos posteriores, las reglas fijadas en esta sentencia tuvieron que irse reforzando ante la falta de reglamentación por parte del Congreso. Es el caso de un joven que había sido reclutado pese a haber presentado objeción de conciencia por pertenecer a la Iglesia Pentecostal, que prohíbe tomar las armas y se opone al militarismo. La Corte resaltó que en la sentencia C-728 de 2009 determinó la existencia de la objeción de conciencia al servicio militar, que para ser ejercida no dependía de la expedición de una regulación, y reiteró que mientras no existiera legislación sobre el tema, la acción de tutela constituiría el mecanismo idóneo para la protección de los derechos del objetor. En esta sentencia, además de resolver desincorporar al accionante, la Corte ordenó al Ministerio de Defensa implementar una campaña de divulgación de la sentencia C-728 de 2009 (Corte Constitucional, 2012a).
Más adelante, un joven presentó acción de tutela porque su declaratoria como objetor de conciencia por ser ministro de la iglesia Testigos de Jehová no había sido respondida, aunque su vinculación al servicio fue aplazada. A pesar de que la Corte constató que existía carencia actual de objeto porque el accionante ya había sido exonerado, se pronunció para reiterar que la falta de regulación no excusa a las autoridades militares de tramitar las solicitudes de objeción de conciencia de acuerdo con la sentencia C-728 de 2009 (Corte Constitucional, 2012b).

Aunque la Corte reconoció que la objeción podía estar basada en convicciones religiosas, éticas, morales o filosóficas, los casos que se han llevado por vía de revisión de tutela a la Corte Constitucional han estado restringidos a objeciones basadas en creencias religiosas, situación que coincide en los ámbitos laboral y educativo. Teniendo en cuenta que en materia del servicio militar, de acuerdo con la Corte la objeción de conciencia es protegible cuando hay creencias profundas, fijas y sinceras, y que el requisito de verificación de estas condiciones puede darse más fácilmente desde el aspecto religioso cuando se hace parte de una iglesia o se practican los ritos y ceremonias de la comunidad de creyentes, los casos en que se argumente la objeción con base en convicciones éticas, morales o filosóficas plantearán mayores debates sobre bajo qué criterios y cómo probar la seriedad de estas convicciones. 


\section{B. El derecho a la objeción de conciencia frente al derecho al aborto legal}

Dado el carácter de derecho humano reproductivo de la interrupción voluntaria del embarazo (IVE) ${ }^{10}$ (Corte Constitucional, 2006), así como el carácter de derecho fundamental que le ha reconocido la jurisprudencia (Corte Constitucional, 2010c), el ejercicio del derecho a la objeción de conciencia en este campo implica un verdadero enfrentamiento de derechos. Sin embargo, a diferencia del ejercicio de dicha objeción en esferas donde se enfrenta a obligaciones y no a derechos, como en la prestación del servicio militar, frente a obligaciones laborales y educativas, e incluso frente al derecho a la salud, los debates en torno a su extensión y límites han sido mucho más álgidos.

En 2006, año para el que la objeción de conciencia en el ámbito estudiantil y laboral había sido reconocida como expresión de las libertades de conciencia y religiosa, y en el que aún no había sido expedida la sentencia de constitucionalidad que reconoció la posibilidad de objetar conciencia al servicio militar obligatorio, la Corte Constitucional emitió la sentencia C-355 de 2006. En ella declaró constitucional de forma condicionada el artículo 122 del Código Penal

10 Las circunstancias en que se puede hacer ejercicio del derecho a la IVE son, de acuerdo con la sentencia C-355 de 2006, las siguientes: (i) Cuando la continuación del embarazo constituya peligro para la vida o la salud de la mujer, certificada por un médico; (ii) Cuando exista grave malformación del feto que haga inviable su vida, certificada por un médico; y, (iii) Cuando el embarazo sea el resultado de una conducta, debidamente denunciada, constitutiva de acceso carnal o acto sexual sin consentimiento, abusivo o de inseminación artificial o transferencia de óvulo fecundado no consentidas, o de incesto (Corte Constitucional, 2006). que prohibía totalmente el aborto, bajo el entendido de que de ahí en adelante las mujeres y niñas pueden acceder a un aborto cuando su vida o salud (física o mental) está en riesgo, cuando el feto tiene malformaciones incompatibles con la vida extrauterina y cuando el embarazo es producto de violación, incesto o de inseminación o transferencia de óvulo no consentidas. La declaración de constitucionalidad condicionada se basó en que una prohibición absoluta del aborto es violatoria de los derechos fundamentales y humanos de las mujeres, entre ellos los sexuales y reproductivos.

Así, desde la expedición de la sentencia C-355 de 2006, la Corte indicó que la objeción de conciencia solo podía ser ejercida por personas naturales y no por personas jurídicas o por el Estado. $Y$ aunque hubo voces de magistrados disidentes, ${ }^{11}$ que señalaron que dicha regla no había sido discutida, esta ha sido la postura constante y reiterada de la Corte en distintas sentencias en que ha resuelto tutelas instauradas por mujeres que buscan la protección de su derecho a la IVE (Corte Constitucional, 2008, 2009b, 2010b, 2011 y 2012). ${ }^{12}$

11 En oposición a esta postura se pueden ver los salvamentos de voto de los magistrados Monroy Cabra y Escobar Gil.

12 La sentencia T-627 de 2012, con ponencia del magistrado Humberto Sierra Porto, no aborda el caso de una mujer que solicita la protección de su derecho a la IVE, sino de una tutela interpuesta por 1280 mujeres colombianas que reclamaban la protección de su derecho a la información en salud sexual y reproductiva, que consideraban vulnerado por el procurador general de la Nación al expedir, entre otras actuaciones, circulares en que afirmaba que la objeción de conciencia podía ejercerse de forma colectiva o por instituciones, contrariando lo establecido por la Corte Constitucional. En este caso, la Corte reafirmó que la jurisprudencia es clara en que la objeción de conciencia no se puede ejercer de forma colectiva o institucional (2012c). 
De esta manera, desde 2006 la Corte se anticipó y zanjó el debate no existente en los escenarios ya expuestos en los apartados anteriores, en donde la objeción de conciencia siempre ha sido ejercida por personas naturales y nunca por personas jurídicas. Es más, incluso en ámbitos donde la objeción de conciencia ha sido reconocida ética y legalmente, como en la prestación de servicios médicos, no se conocía de una persona jurídica prestadora de servicios de salud que intentara negarse a hacerlo con base en dicha objeción. Es llamativo que estos intentos sin fundamento en el marco de la objeción de conciencia en los ámbitos laboral, estudiantil y del servicio militar, aparecieran únicamente frente a la IVE.

Particularmente importante es la sentencia T-388 de 2009, en que se usó por primera vez el término derecho a la objeción de conciencia en el ámbito de la IVE, y se resaltó como fundamento de la imposibilidad para hacer uso de este derecho por parte de las instituciones, su pertenencia al sistema de seguridad social en salud y, por tanto, su rol como garantes de los derechos de los usuarios, así como la inexistencia de algo que pudiera denominarse conciencia que les permitiera objetar con base en íntimas convicciones:

En efecto, el ejercicio de la objeción de conciencia no se asimila a la simple opinión que se tenga sobre un asunto; por el contrario, son las más íntimas y arraigadas convicciones del individuo las que pueden servir como fundamento para el ejercicio de este derecho. Esta característica es ajena a las personas jurídicas, que en su constitución y ejercicio pueden con- cretar principios como la libertad de empresa o derechos fundamentales de sus socios, mas éstos no podrán nunca transmitirles caracteres éticos y morales propios y exclusivos de las personas naturales.

(...) En este punto no resultaría válido diferenciar, para el tema en concreto, entre las personas jurídicas privadas y públicas. Las principales razones serán que se trata de la prestación del servicio público de salud, dentro del sistema público de salud establecido por el Estado, en donde se ve involucrada la protección de derechos fundamentales de los usuarios (Corte Constitucional, 2009b).

A pesar de ser esta la posición mayoritaria, es relevante señalar que el magistrado Henao Pérez (2009) se pronunció en la aclaración de voto a la sentencia referida, precisamente en cuanto a los fundamentos considerados por la Corte para excluir la objeción de conciencia de las personas jurídicas. En su sentir, las instituciones sí pueden tener convicciones confesionales o religiosas, y por tanto sí podrían abstenerse de prestar servicios de IVE, salvo en casos en que sean las únicas instituciones que prestan servicios de salud en un lugar, o en casos en que se encuentre en riesgo la vida o integridad de la mujer o niña solicitante de dicho procedimiento.

De otra parte, las sentencias sobre IVE también han sido explícitas en que la objeción de conciencia debe ejercerse individualmente, y no de manera colectiva (Corte Constitucional, 2008a, 2009b, 2011b y 2012c). Igualmente, la jurisprudencia ha tenido que ser enfática en que los jueces no pueden ejercer el derecho a la obje- 
ción de conciencia para evitar proteger mediante sus pronunciamientos el derecho a la IVE de las mujeres que se encuentren en las causales señaladas por la sentencia C-355 de 2006 (Corte Constitucional, 2008, 2009b, 2010, 2011 y 2012). Así, se ha explicado que los jueces no pueden objetar conciencia porque:

[C] ]uando un funcionario o funcionaria judicial profiere su fallo no está en uso de su libre albedrío. En estos casos el juez se encuentra ante la obligación de solucionar el problema que ante él se plantea -art. 230 de la Constitución-, con base en la Constitución y demás normas que compongan el ordenamiento jurídico aplicable. (...) Lo anterior no significa que como persona no tenga la posibilidad de ejercer sus derechos fundamentales; significa que en su labor de administrar justicia sus convicciones no lo relevan de la responsabilidad derivada de su investidura, debiendo administrar justicia con base única y exclusivamente en el derecho, pues es esa actitud la que hace que en un Estado impere la ley y no los pareceres de las autoridades públicas (...).

Adicionalmente, admitir la posibilidad de objetar por motivos de conciencia la aplicación de un precepto legal determinado significa, en el caso de las autoridades jurisdiccionales, aceptar la denegación injustificada de justicia y obstaculizar de manera arbitraria el acceso a la administración de justicia (Corte Constitucional, 2009b).

Al igual que frente a la imposibilidad de ejercer la objeción de conciencia por instituciones, que no tenía antecedentes en los demás ámbitos estudiados para este artículo, la objeción de conciencia también intentó ser usada de mane- ra colectiva, principalmente mediante formatos que dejan de lado las características de seriedad y profundidad exigidas en las otras esferas para que sea protegible, e incluso ha intentado ser usada por funcionarios judiciales como una casual más de impedimento para fallar casos de aborto legal, a pesar de que no está contemplada entre las casuales taxativas y legales.

En contraposición a las anteriores exclusiones a la titularidad del derecho a la objeción de conciencia en que la jurisprudencia ha tenido que ser explícita, se ha reconocido y protegido su uso por el personal médico que se enfrenta directamente a la realización del procedimiento, excluyendo el personal administrativo que se encarga de la gestión de la atención, así como el personal médico que prepara a la mujer para la intervención o le da atención después de esta. Esta regla se mantiene en concordancia con lo previsto por la jurisprudencia constitucional en el ámbito general de la salud, que ya fue expuesto, así como con las reglas de la práctica médica.

En los casos de objeción de conciencia de profesionales de la salud que intervienen directamente en el procedimiento, la jurisprudencia ha establecido que la forma de proteger tanto el derecho del objetor como el derecho a la IVE de las mujeres, es que aquél remita inmediatamente a las solicitantes a otro profesional de la salud no objetor. De este modo se protegen las convicciones del profesional de la salud y se garantiza la prestación del servicio de IVE.

A la anterior regla se ha añadido que corresponde a las EPs tener disponibilidad del servicio en 
todo el territorio nacional y en toda su red de prestadores, así como la información de dónde se encuentran los profesionales de su red que prestan estos servicios (Corte Constitucional, 2006, 2012c y 2009b). También se exige que, en estos casos, la objeción se presente por escrito y se expliquen los motivos de la objeción y a quién se remite la mujer o niña, para que los Tribunales de Ética Médica hagan un control de procedencia y pertinencia de la objeción (Corte Constitucional, 2006 y 2009b).

Es en ámbitos distintos en donde se reconoce por primera vez el derecho a la objeción de conciencia en la jurisprudencia de la Corte Constitucional. De una parte, frente a una obligación pura como es la prestación del servicio militar obligatorio que tiene como trasfondo fines constitucionales, pero no derechos, espacio en que se da un salto de la negativa a reconocer la posibilidad a establecer directamente el derecho a objetar. De otra parte, en un ámbito en que se reconoce el derecho a la objeción de conciencia frente a otro derecho, es decir frente al derecho de las mujeres a optar por una IVE y a acceder a los servicios de salud necesarios para hacer efectiva esa opción.

\section{CONCLUSIONES}

La jurisprudencia de la Corte Constitucional tuvo una evolución paulatina en relación con la posibilidad de ejercer la objeción de conciencia frente a obligaciones estudiantiles, con una primera etapa durante los años 90 cuando fue negada tajantemente, para pasar luego a su re- conocimiento en los inicios de los años 2000 en los mismos términos que frente a obligaciones laborales.

En el campo de la salud, donde se estudiaron casos sobre libertad religiosa de forma genérica, y no de ejercicio de la objeción de conciencia en forma estricta, la jurisprudencia ha sido constante en los parámetros dentro de los que opera tal libertad. Así, señaló que no se trata de un derecho absoluto, puesto que encuentra límites en la vida e integridad de quien la ejerce y en las de terceros, en los demás derechos de otras personas, así como en la seguridad, la moralidad y la salubridad públicas. Así mismo, en los casos en que se ha ejercido efectivamente la objeción de conciencia por parte de personal médico frente a una obligación contractual de prestación del servicio, la jurisprudencia con base, entre otros argumentos, en la existencia de una normatividad que la reconoce explícitamente y establce los parámetros para su uso, ha protegido esta expresión de la libertad de conciencia. Sin embargo, la jurisprudencia en ningún momento le da el carácter de derecho; esto solo ocurrirá frente a un servicio de salud específico que, a la vez, ha sido reconocido como derecho: la IVE.

En el año 2009 la Corte Constitucional coincidió en reconocer el derecho a la objeción de conciencia frente al aborto legal y frente al servicio militar. En este último ámbito la jurisprudencia da un salto, por oposición a una evolución paulatina, entre la negativa a considerar la sola posibilidad de objetar esta obligación y su reconocimiento como derecho. 
Si bien la jurisprudencia de las esferas laboral y estudiantil hace alusiones a que para que la objeción sea protegible las convicciones deben ser serias, sinceras o genuinas, y no un simple pretexto para omitir el cumplimiento de una obligación, es en la sentencia C-728 de 2009 donde establece un listado de características que las convicciones deben cumplir para ser fundamento legítimo de una objeción al servicio militar: deben ser profundas, fijas y sinceras. Estas características deben ser probadas mediante manifestaciones externas por parte del objetor.

Aunque la jurisprudencia en materia de servicio militar establece, al igual que la de IVE, que la objeción de conciencia puede fundamentarse en convicciones religiosas, morales, éticas o filosóficas, en el caso de la IVE no ha exigido ni características tan precisas, ni prueba de estas, pero sí que se haga por escrito y manifestando las razones que la fundamentan.

Lo estricto de los requisitos de la objeción de conciencia en la jurisprudencia sobre servicio militar, donde lo que se objeta es una obligación, contrasta con la menor rigurosidad, no inexistente del todo, se aclara, que se hace al fundamentar la objeción frente al derecho a la IVE. Lo anterior, pese a que en aplicación de las reglas sobre libertad religiosa expresadas en casos de su ejercicio frente a la salud, es distinta la extensión de protección de la objeción de conciencia cuando se enfrenta a obligaciones constitucionales, legales o contractuales, que cuando entra en contraposición con derechos de terceras personas.
Es en este ámbito donde en aplicación de los límites constitucionales a la libertad religiosa, consistentes en que esta no puede afectar la vida ni la integridad propias o de terceros, ni, en general, los derechos de terceras personas, adquieren mayor relevancia. El conflicto entre derechos implica que las restricciones al uso de la objeción de conciencia aumentan y, por lo tanto, se busca armonizar el ejercicio de los derechos en pugna. Es por esta razón que en materia del derecho a la IVE, la jurisprudencia ha solucionado la confrontación con la fórmula consistente en que se respete la objeción de conciencia del personal médico, pero para proteger los derechos fundamentales de la solicitante de la IVE se la debe remitir a otro profesional que se sepa no es objetor y está disponible.

Ahora bien, en el caso particular de la objeción de conciencia al servicio militar, la desatención del legislador en regularla ha generado grandes dificultades para la efectividad del derecho. Existen graves desconocimientos por parte de las autoridades de reclutamiento y del Ejército Nacional, quienes niegan incluso los contenidos mismos de la sentencia C-728 de 2009. El procedimiento sigue sin estar claro, aunque la acción de tutela ha sido una manera claramente efectiva para reclamarlo.

Las dificultades en el uso de la objeción de conciencia en el servicio militar, que persisten a pesar de su reconocimiento como derecho, encuentran la otra cara de la moneda en los obstáculos que ha planteado para las mujeres que optan por una IVE, el uso indebido de este derecho mediante formas que no tienen funda- 
mento en su marco general, como las objeciones de conciencia institucional, colectiva, y por parte de funcionarios judiciales, que han debido ser frenadas por la jurisprudencia con la declaración explícita de estar prohibidas.

Cabe plantear que el ejercicio de la objeción de conciencia tanto frente a meras obligaciones como frente a derechos, hasta ahora se ha basado en convicciones religiosas, y no en ideas desligadas de esta connotación como las éticas, las morales o las filosóficas.

Teniendo en cuenta los altos niveles de exigencia en las características, así como en la prueba de las convicciones para el servicio militar obligatorio, y que de alguna manera pueden sortearse con la práctica de un culto o la pertenencia a una iglesia, vale la pena preguntarse cómo podrán demostrarse estos elementos por un objetor que aduce convicciones filosóficas, éticas o morales. También es válido preguntarse si el que pueda ser más difícil para este tipo de objetores que para los de tipo religioso podría considerarse o no una diferenciación que busca un fin legítimo por medios proporcionados.

Al mismo tiempo, y como las caras de un enfrentamiento entre derechos (la objeción y la IVE), la invocación de convicciones distintas a las religiosas como fundamento de la objeción en este ámbito seguramente generará nuevos debates, que deberán ser resueltos en el marco general de las reglas establecidas por la jurisprudencia para el ejercicio de la objeción de conciencia en otras materias, y que deberán tener en cuenta que se trata de un enfrentamiento en- tre derechos y no de la simple objeción a una obligación, aún si puede afectar intereses jurídicos protegidos. De acuerdo con lo expuesto en este artículo, será necesario que estos debates tengan en cuenta los desarrollos de la jurisprudencia sobre colisión entre derechos, el marco general que ha establecido sobre la objeción de conciencia, la jurisprudencia y el marco legal sobre las libertades de conciencia, de pensamiento y de cultos, así como la jurisprudencia de los derechos fundamentales y humanos, entre ellos los sexuales y reproductivos de las mujeres.

\section{Referencias}

Araújo Rentería, J. (2001). Salvamento de voto a la sentencia C-740 de 2001. Bogotá, D. C.

Cepeda Espinosa, M. (2001). Salvamento de voto a la sentencia C-740 de 2001. Bogotá, D. C.

Cifuentes Muñoz, E. (1993). Salvamento de voto a la sentencia T-593A de 1993. Bogotá, D. C.

Cifuentes Muñoz, E. (1999). Salvamento de voto a la sentencia T-877 de 1999. Bogotá, D. C.

Cifuentes Muñoz, E., Gaviria Díaz, C. y Martínez Caballero, A. (1994). Salvamento de voto a la sentencia C-511 de 1994. Bogotá, D. C.

Congreso de la República de Colombia. (1993). Ley 48 de 1993. Diario Oficial n. ${ }^{\circ} 40.777$.

Corte Constitucional. (1992). Sentencia T-409 de 1992. M. P.: José Gregorio Hernández. 
Corte Constitucional. (1993a). Sentencia T-244 de 1993. M. P.: Vladimiro Naranjo Mesa.

Corte Constitucional. (1993b). Sentencia T-547 de 1993. M. P.: Alejandro Martínez Caballero.

Corte Constitucional. (1993c). Sentencia T593A de 1993. M. P.: Carlos Gaviria Díaz.

Corte Constitucional. (1994a). Sentencia T-411 de 1994. M. P.: Vladimiro Naranjo Mesa.

Corte Constitucional. (1994b). Sentencia C-511 de 1994. M. P.: Fabio Morón Díaz.

Corte Constitucional. (1995a). Sentencia T-075 de 1995. M. P.: Carlos Gaviria Díaz.

Corte Constitucional. (1995b). Sentencia T-363 de 1995. M. P.: José Gregorio Hernández Galindo.

Corte Constitucional. (1995c). Sentencia C-561 de 1995. M. P.: José Gregorio Hernández Galindo.

Corte Constitucional. (1996). Sentencia T-474 de 1996. M. P.: Fabio Morón Díaz.

Corte Constitucional. (1997). Sentencia C-616 de 1997. M. P.: Vladimiro Naranjo Mesa.

Corte Constitucional. (1998). Sentencia T-588 de 1998. M. P.: Eduardo Cifuentes Muñoz.

Corte Constitucional. (1999). Sentencia T-877 de 1999. M. P.: Antonio Barrera Carbonell.
Corte Constitucional. (2001a). Sentencia C-740 de 2001. M. P.: Álvaro Tafur Galvis.

Corte Constitucional. (2001b). Sentencia T-982 de 2001. M. P.: Manuel José Cepeda Espinosa.

Corte Constitucional. (2001c). Sentencia T-1059 de 2001. M. P.: Jaime Araújo Rentería.

Corte Constitucional. (2002a). Sentencia T-659 de 2002. M. P.: Clara Inés Vargas Hernández.

Corte Constitucional. (2002b). Sentencia T-823 de 2002. M. P.: Rodrigo Escobar Gil.

Corte Constitucional. (2004a). Sentencia T-332 de 2004. M. P.: Jaime Córdoba Triviño.

Corte Constitucional. (2004b). Sentencia T-447 de 2004. M. P.: Eduardo Montenegro Lynnet.

Corte Constitucional. (2005a). Sentencia T-026 de 2005. M. P.: Humberto Sierra Porto.

Corte Constitucional. (2005b). Sentencia T-471 de 2005. M. P.: Clara Inés Vargas Hernández.

Corte Constitucional. (2006). Sentencia C-355 de 2006. M. P.: Jaime Araújo Rentería y Clara Inés Vargas Hernández.

Corte Constitucional. (2007). Sentencia C-036 de 2007. M. P.: Clara Inés Vargas.

Corte Constitucional. (2008a). Sentencia T-209 de 2008. M. P.: Clara Inés Vargas Hernández. 
Corte Constitucional. (2008b). Sentencia T-946 de 2008. M. P.: Jaime Córdoba Triviño.

Corte Constitucional. (2009a). Sentencia T-327 de 2009. M. P.: Jorge Ignacio Pretelt Chaljub.

Corte Constitucional. (2009b). Sentencia T-388 de 2009. M. P.: Humberto Sierra Porto.

Corte Constitucional. (2009c). Sentencia C-728 de 2009. M. P.: Gabriel Eduardo Mendoza Martelo.

Corte Constitucional. (2009d). Sentencia T-839 de 2009. M. P.: María Victoria Calle.

Corte Constitucional. (2010a). Auto 327 de 2010. M. P.: Humberto Sierra Porto.

Corte Constitucional. (2010b). Sentencia T-052 de 2010. M. P.: Mauricio González Cuervo.

Corte Constitucional. (2010c). Sentencia T-585 de 2010. M. P.: Humberto Sierra Porto.

Corte Constitucional. (2011a). Auto 085A de 2011. M. P.: Humberto Sierra Porto.
Corte Constitucional. (2011b). Sentencia T-841 de 2011. M. P.: Humberto Sierra Porto.

Corte Constitucional. (2011c). Sentencia C-900 de 2011. M. P.: Jorge Ignacio Pretelt Chaljub.

Corte Constitucional. (2012a). Sentencia T-018 de 2012. M. P.: Luis Ernesto Vargas Silva.

Corte Constitucional. (2012b). Sentencia T-375 de 2012. M. P.: Luis Ernesto Vargas Silva.

Corte Constitucional. (2012c). Sentencia T-627 de 2012. M. P.: Humberto Sierra Porto.

Henao Pérez, J. C. (2009). Aclaración de voto a la sentencia T-388 de 2009. Bogotá, D. C.

Henao Pérez, J. C. (2010). Salvamento de voto a la sentencia T-052 de 2010. Bogotá, D. C.

Montealegre Lynnet, E. (2001). Salvamento de voto a la sentencia C-740 de 2001. Bogotá, D. C. 